\title{
CLINICAL PROFILE AND OUTCOME OF SCORPION STING ENVENOMATION IN CHILDREN ADMITTED IN A TERTIARY CARE HOSPITAL
}

\author{
Hemachitra Jagannathan', Kannan Ramamoorthy², Sridevi A. Naaraayan ${ }^{3}$
}

${ }^{1}$ Associate Professor, Department of Paediatrics, Government Tiruvarur Medical College, Tiruvarur.

${ }^{2}$ Associate Professor, Department of Paediatrics, Government Tiruvarur Medical College, Tiruvarur.

${ }^{3}$ Assistant Professor, Department of Paediatrics, Institute of Child Health and Hospital for Children, Egmore, Chennai.

ABSTRACT
BACKGROUND
Scorpion sting envenomation is life threatening and a common public health problem in children.
OBJECTIVES
The primary objective was to characterize the epidemiological and clinical features of scorpion sting envenomation in children.
The secondary objective was to determine the factors affecting duration of hospital stay.

\section{METHODS}

This retrospective descriptive study included children less than 12 years admitted in the paediatric ward with history of scorpion sting from Jan 2015 to Dec 2015. Epidemiological and clinical data such as age, sex, time and site of bite, pain, paraesthesia, swelling, sweating, vomiting, pre-hospital treatment, heart rate, blood pressure, X-ray, ECG findings, time and number of doses of prazosin administration, duration of hospital stay were collected. Parameters were expressed as percentage. Factors were analysed using Univariate and multivariate analyses.

\section{RESULTS}

Among 159 children the observations made were common age group 2-6 years (44.5\%), males (63\%), nocturnal bites (53.8\%), lower limb bites (52.2\%), pain (33.8\%), admission within 2 hours (81.25\%), pre-hospital treatment (28.7\%) class I symptoms (43\%) and ECG changes in (11.3\%); 89.3\% received prazosin. Univariate analysis identified abnormal heart rate, S3 gallop, cold extremities, weak pulse, prolonged capillary refill time, abnormal systolic blood pressure and ECG changes as significant risk factors for prolonged hospital stay, whereas cold extremities and ECG changes were significant risk factors in multivariate analysis.

\section{CONCLUSION}

Demographic parameters and clinical profile are described. Cold extremities and ECG abnormalities were significantly associated with prolonged hospital stay.

\section{KEYWORDS}

Envenomation, Prazosin, Scorpion.

HOW TO CITE THIS ARTICLE: Jagannathan H, Ramamoorthy K, Naaraayan SA. Clinical profile and outcome of scorpion sting envenomation in children admitted in a tertiary care hospital. J. Evolution Med. Dent. Sci. 2016;5(57):3941-3945, DOI: $10.14260 /$ jemds/2016/900

\section{INTRODUCTION}

Scorpion envenomation is an important public health hazard in tropical and subtropical regions. Its high incidence in the tropical areas may be caused by some factors such as warmer weather conditions, the existence of substandard housing conditions, resting in outdoors and insufficient supply of information to inhabitants about measures to prevent scorpion envenomation.[1] The Indian red scorpion (Buthus Tamulus), commonly found in India is one of the most dangerous species of scorpions Figure 2. They are nocturnal arachnids. They live in warm dry regions. They inhabit commonly the crevices of dwellings, underground burrows, underlogs and banana plantations. They emerge only at night, thus most stings are reported at night. Stings are primarily due to accidental contact with scorpion.

Financial or Other, Competing Interest: None.

Submission 05-06-2016, Peer Review 04-07-2016,

Acceptance 11-07-2016, Published 16-07-2016.

Corresponding Author:

Hemachitra Jagannathan,

F1, B, Block, Vijay Balajee Flats,

No. 6, Sabari Salai,

Madipakkam

Chennai 600091.

E-mail: hemachitramkumar@gmail.com

DOI: $10.14260 /$ jemds $/ 2016 / 900$
The venom contains numerous free amino acids, serotonin, hyaluronidase and various enzymes that act on trypsinogen. The toxin acts by opening sodium channel at presynaptic nerve terminals and inhibit calcium dependant potassium channels. Autonomic storm is thus initiated. Alpha receptor stimulation results in hypertension, tachycardia, myocardial dysfunction, pulmonary oedema and cool extremities. Direct effect of toxins on neurons could contribute to seizures and encephalopathy. The severity of scorpion sting envenomation is classified as per Abroug's classification.[2] This study was aimed to describe the demographic parameters, clinical features, complications and outcome of scorpion sting envenomation in children admitted in a tertiary care hospital at Tiruvarur.

\section{METHODS}

This retrospective descriptive study was conducted in Government Tiruvarur Medical College Hospital. Children less than 12 years of age who were admitted in the paediatric medical ward with history of scorpion sting from Jan 2015 to Dec 2015 were included. There was no exclusion criteria. Clinical and epidemiological data were obtained from the medical records and comprised of the following variables like age, sex, time of sting, site of sting, symptoms like pain, 
swelling, sweating, salivation, vomiting, cold extremities, altered sensorium. Details of pre-hospital treatment were noted; it included whether any pre-hospital therapy was given and if so drugs used in pre-hospital treatment. Time interval between sting and admission was obtained from the medical records. Clinical parameters like heart rate, presence or absence of S3 gallop, peripheral pulse character, capillary refill time, blood pressure, respiratory rate, presence of subcostal retractions, priapism at the time of admission were noted. X-ray changes, ECG abnormalities, administration of inotropes, time interval between sting and prazosin administration, clinical classification based on Abroug's classification and duration of hospital stay were also recorded.

\section{Operational Definitions Used}

Time of sting from $7 \mathrm{AM}$ to $7 \mathrm{PM}$ was taken as day time and from 7 PM to 7 AM taken as night. Details of pre-hospital treatment including the drugs used were also collected. Tachycardia, bradycardia, hypertension, hypotension, tachypnoea, bradypnoea, shock and myocarditis were defined as per PALS (Paediatric Advanced Life Support). X-ray features of cardiomegaly, increased pulmonary vascular markings were considered abnormal. Abnormalities in rate and rhythm, prolonged PR interval, ST and T changes were considered as abnormal ECG findings.

\section{Statistical Analysis}

Statistical analysis was done using SSPS version 21. Prevalence of various demographic and clinical parameters is expressed in proportions. The relation between independent variables (Clinical parameters) and the dependent variable (Duration of hospital stay) was determined using univariate analysis and the parameters with statistically significant relation were subjected to multivariate logistic regression. $P$ value less than 0.05 was considered statistically significant. Crude and adjusted odds for each significant parameter were expressed with $95 \%$ confidence interval.

\section{RESULTS}

Totally, 159 children under the age group of 12 years were studied. Age and sex distribution is shown in Figure 1. It can be observed that almost twice the number of boys were affected compared to girls. There was not much diurnal variation occurring in bites with $53.8 \%$ occurring during the night, i.e. $7 \mathrm{pm}$ to $7 \mathrm{am}$ and the almost equal proportion $(46.2 \%)$ occurring during day. Only 34 (21.4\%) of bites occurred outdoor, whereas the rest 125 (78.6\%) occurred indoors. Most common site was lower limbs in 83 (52.2\%) children followed by upper limbs in 51 (32.1\%), abdomen in $13(8.2 \%)$ and face in $12(7.5 \%)$ children.

Local symptoms reported were pain in 54 (34\%) children and local swelling in 10 (6.3\%) children. Paraesthesia was seen in only $3(1.9 \%)$ children. The common systemic symptoms reported were sweating 43 (27\%), vomiting 37 (23.3\%), increased salivation 12 (7.5\%) and cold extremities 5 (3.1\%). Central nervous system symptoms like irritability and altered sensorium were present in 17 (10.7\%) and 6 (3.8\%) of children respectively.
129 (81.1\%) of the cases got admitted within two hours of sting. Pre-hospital treatment was taken by 40 (25.2\% [95\% CI $18.45-39.95 \%]$ ) of the cases. Out of these, only 20 (12.6\%) of children had received prazosin. Others had received corticosteroids and antihistamines.

Among clinical signs, tachycardia was seen in 58 (36.5\%) and bradycardia in $2(1.3 \%)$ children. S3 gallop was seen in 5 (3.1\%) children. Signs of poor peripheral perfusion observed were cold extremities in 37 (23.3\%), weak peripheral pulse in $21(13.2 \%)$ and prolonged capillary refill time (More than 3 seconds) in 12 (7.5\%). Systolic hypertension was observed in $46(28.9 \%)$, while $4(2.5 \%)$ had hypotension. Diastolic hypertension was observed in 39 (24.5\%), while 3 (1.9\%) had hypotension; 4 (2.5\%) children were tachypnoeic, while 1 $(0.6 \%)$ had subcostal retractions. Priapism was seen in 7 (4.4\%) children and encephalopathy in 4 (2.5\%).

The X-ray changes of cardiomegaly and increased pulmonary vascular markings were observed in only $2(1.3 \%)$ patients. ECG changes were observed in $18(11.3 \%)$ patients. Tall T waves and ST segment elevation were the common ECG findings; $143(89.3 \%)$ of the children were administered prazosin. Intravenous fluids were used in treatment of $126(79.2 \%)$ children, while 22 (13.8\%) required inotropes. Early administration of prazosin within 4 hours was noted in $144(90.6 \%)$ of the patients; $17(10.7 \%)$ children were administered 1 dose of prazosin, while 54 (34\%) received 2 doses, $72(45.3 \%)$ received 3 doses and another $16(10.1 \%)$ received 4 doses of prazosin respectively; 52 (32.7\%) patients had class I symptoms, $50(31.4 \%)$ had class 2 symptoms and $17(10.7 \%)$ had class 3 symptoms. No mortality was noted during the study period; $32(20.1 \%)$ children stayed in hospital beyond 72 hours.

The class of severity was found to have a significant impact on duration of stay as shown in Table 1 . Children with class 3 symptoms had a prolonged hospital stay when compared to class 1 and 2 and this is found to be statistically significant. Hence, individual clinical parameters were analysed for association with duration of stay using univariate analysis and the results are shown in Table 2. Abnormal heart rate, S3 gallop, cold extremities, weak peripheral pulse, prolonged capillary refill time, abnormal systolic blood pressure and ECG changes were identified as significant risk factors for prolonged hospital stay. All these variables which were statistically significant in univariate analysis were subjected to multivariate analysis and the results are depicted in Table 3. Cold extremities and ECG abnormalities emerged as independent significant risk factors for prolonged hospital stay in children admitted with scorpion sting envenomation.

\begin{tabular}{|c|c|c|c|c|}
\hline Severity & $\begin{array}{c}\text { More than } \\
\mathbf{7 2} \text { hours N } \\
\text { (\%) }\end{array}$ & $\begin{array}{c}\text { Less than } \\
\mathbf{7 2} \text { hours N } \\
(\%)\end{array}$ & $\mathbf{x}^{\mathbf{2}}$ & $\begin{array}{c}\text { P } \\
\text { value }\end{array}$ \\
\hline Class 1 & $4(7.7 \%)$ & $48(92.3 \%)$ & & \\
Class 2 & $12(24 \%)$ & $38(76 \%)$ & & $<$ \\
Class 3 & $15(88.2 \%)$ & $2(11.8 \%)$ & 39.35 & $0.001^{*}$ \\
TOTAL & $31(26.1 \%)$ & $88(73.9 \%)$ & & \\
\hline Table 1: Comparison of Severity of Scorpion Sting and \\
Duration of Hospital Stay
\end{tabular}

* Highly significant 


\begin{tabular}{|c|c|c|c|c|c|c|}
\hline \multirow[b]{2}{*}{ Variable } & \multirow[b]{2}{*}{ Category } & \multicolumn{2}{|c|}{ Duration of Stay } & \multirow[b]{2}{*}{$x^{2}$} & \multirow[b]{2}{*}{ p value } & \multirow[b]{2}{*}{$\begin{array}{c}\text { Odd's Ratio } \\
\text { (95\% CI) }\end{array}$} \\
\hline & & $\begin{array}{c}\text { More than } 72 \text { hours } \\
\text { N (\%) }\end{array}$ & $\begin{array}{c}\text { Less than } 72 \text { hours } \\
\text { N (\%) }\end{array}$ & & & \\
\hline \multirow{2}{*}{ Heart rate } & Abnormal & $21(35 \%)$ & $39(65 \%)$ & \multirow{2}{*}{13.262} & \multirow{2}{*}{$\begin{array}{c}<0.001 \\
\text { HS }\end{array}$} & \multirow{2}{*}{$\begin{array}{c}4.308 \\
(1.895-9.792) \\
\end{array}$} \\
\hline & Normal & $11(11.1 \%)$ & $88(88.9 \%)$ & & & \\
\hline \multirow{2}{*}{ S3 gallop } & Present & $4(80 \%)$ & $1(20 \%)$ & \multirow{2}{*}{11.512} & \multirow{2}{*}{$0.006 \mathrm{HS}$} & \multirow{2}{*}{$\begin{array}{c}18.0 \\
(1.937-167.277)\end{array}$} \\
\hline & Absent & $28(18.2 \%)$ & $126(81.8 \%)$ & & & \\
\hline \multirow{2}{*}{ Cold extremities } & Present & $22(59.5 \%)$ & $15(40.5 \%)$ & \multirow{2}{*}{46.410} & \multirow{2}{*}{$<0.001 \mathrm{HS}$} & \multirow{2}{*}{$\begin{array}{c}16.427 \\
(6.536-41.281)\end{array}$} \\
\hline & Absent & $10(8.2 \%)$ & $112(91.8 \%)$ & & & \\
\hline \multirow{2}{*}{ Peripheral pulse } & Weak & $14(66.7 \%)$ & $7(33.3 \%)$ & \multirow{2}{*}{32.602} & \multirow{2}{*}{$<0.001 \mathrm{HS}$} & \multirow{2}{*}{$\begin{array}{c}13.333 \\
(4.742-37.487)\end{array}$} \\
\hline & Normal & $18(13 \%)$ & $120(87 \%)$ & & & \\
\hline \multirow{2}{*}{ Capillary Refill Time } & $>3$ seconds & $10(83.3 \%)$ & $2(16.7 \%)$ & \multirow{2}{*}{32.258} & \multirow{2}{*}{$<0.001 \mathrm{HS}$} & \multirow{2}{*}{$\begin{array}{c}28.409 \\
(5.826-138.533)\end{array}$} \\
\hline & $<3$ seconds & $22(15 \%)$ & $125(85 \%)$ & & & \\
\hline \multirow{2}{*}{ Systolic BP } & Abnormal & $16(32 \%)$ & $34(68 \%)$ & \multirow{2}{*}{6.397} & \multirow{2}{*}{0.018 HS } & \multirow{2}{*}{$\begin{array}{c}2.735 \\
(1.233-6.066)\end{array}$} \\
\hline & Normal & $16(14.7 \%)$ & $93(85.3 \%)$ & & & \\
\hline \multirow{2}{*}{ Diastolic BP } & Abnormal & $12(28.6 \%)$ & $30(71.4 \%)$ & \multirow{2}{*}{2.533} & \multirow{2}{*}{0.121} & \multirow{2}{*}{$\begin{array}{c}1.940 \\
(0.851-0.425)\end{array}$} \\
\hline & Normal & $20(17.1 \%)$ & $97(82.9 \%)$ & & & \\
\hline \multirow{2}{*}{ Priapism } & Present & $3(42.9 \%)$ & $4(57.1 \%)$ & 2254 & & 3.181 \\
\hline & Absent & $29(19.1 \%)$ & $123(80.9 \%)$ & 2.354 & 0.146 & $(0.675-14.998)$ \\
\hline & Present & $14(77.8 \%)$ & $4(22.2 \%)$ & & & 23.917 \\
\hline ECG changes & Absent & $18(12.8 \%)$ & $123(87.2 \%)$ & 41.968 & $<0.001 \mathrm{HS}$ & $(7.087-80.713)$ \\
\hline & Table 2: C & nical Parameters and & uration of Stay - Un & riate $A$ & lysis & \\
\hline
\end{tabular}

HS - Highly Significant

\begin{tabular}{|c|c|c|c|c|}
\hline Variable & Crude Odd's Ratio & Adjusted Odd's Ratio & 95\% Confidence Interval & p value \\
\hline $\begin{array}{c}\text { Heart rate } \\
\text { Abnormal Vs Normal }\end{array}$ & 4.308 & 1.951 & $0.622-6.117$ & 0.252 \\
\hline $\begin{array}{c}\text { S3 Gallop } \\
\text { Present Vs Absent }\end{array}$ & 18.000 & 0.158 & $0.004-6.590$ & 0.333 \\
\hline $\begin{array}{c}\text { Cold extremities } \\
\text { Present Vs Absent }\end{array}$ & 16.427 & 9.596 & $2.632-34.991$ & 0.001 \\
\hline $\begin{array}{c}\text { Peripheral pulse } \\
\text { Weak Vs Normal }\end{array}$ & 13.333 & 0.390 & $0.047-3.258$ & 0.385 \\
\hline $\begin{array}{c}\text { Capillary Refill Time } \\
>3 \text { seconds Vs <3 seconds }\end{array}$ & 28.409 & 3.712 & $0.211-65.229$ & 0.370 \\
\hline $\begin{array}{c}\text { Systolic Blood Pressure } \\
\text { Abnormal Vs Normal }\end{array}$ & 2.735 & 2.804 & $0.433-18.151$ & 0.279 \\
\hline $\begin{array}{c}\text { ECG Changes } \\
\text { Present Vs Absent }\end{array}$ & 23.917 & 9.124 & $1.634-50.940$ & 0.012 \\
\hline \multicolumn{2}{|c|}{ Table 3: Clinical Parameters and Duration of Hospital Stay - Multivariate Logistic Regression Analysis } \\
\hline
\end{tabular}

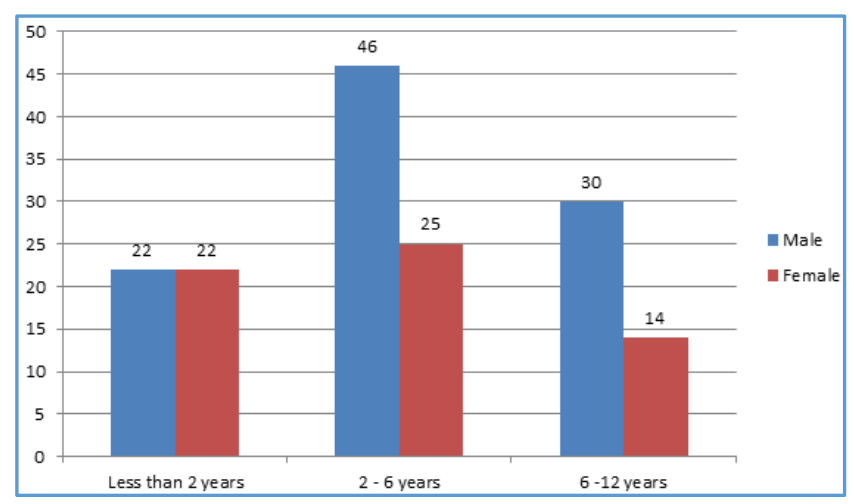

Fig. 1: Age and Sex Distribution

\begin{tabular}{|c|c|}
\hline Category & N \% \\
\hline Class I & $52(32.7 \%)$ \\
\hline Class II & $50(31.4 \%)$ \\
\hline Class III & $17(10.7 \%)$ \\
\hline No classification & $40(25.2 \%)$ \\
\hline \multicolumn{2}{|c|}{ Total } \\
\hline \multicolumn{2}{|c|}{ Table 4: Clinical Classification } \\
\hline
\end{tabular}

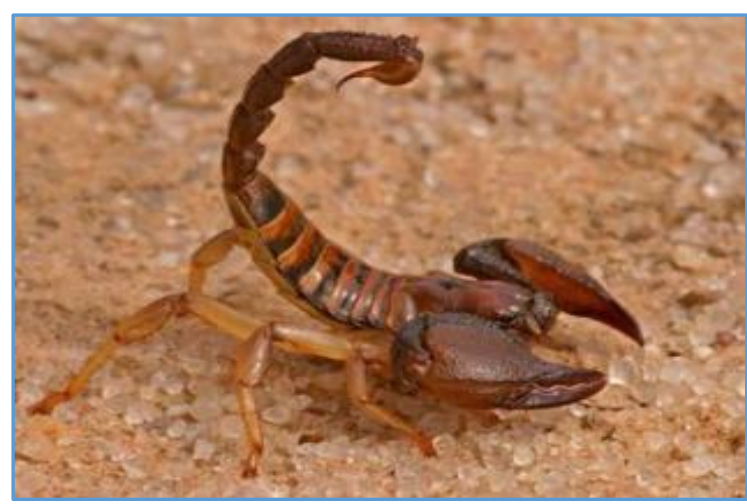

Fig. 2

\section{DISCUSSION}

Features of cholinergic stimulation merge with those of adrenergic stimulation. Vomiting, salivation, sweating, priapism and bradycardia are the common cholinergic features. Tachycardia, hypertension, myocardial dysfunction, pulmonary oedema and shock are the common adrenergic symptoms. 
This study showed that scorpion sting was more common in age group of 2-6 years and male children were more commonly affected than female children. Extremities were the common site of sting. These demographic features were comparable to earlier studies.[3],[4] Pain was the commonest local symptom; sweating, vomiting and irritability were the common systemic symptoms as reported in previous studies.[5]

Pre-hospital treatment was given to $25 \%$ of the patients. Corticosteroids and antihistamines were the commonly used drugs. Prazosin was given alone only in 3.8\% and along with steroids and antihistamines in $8.8 \%$ of the patients. Study by Ramesh Pol et al has showed that dexamethasone alone or in combination with antihistamines is known to potentiate the effect of catecholamines on the cardiovascular system, central nervous system and worsen the encephalopathy.[6] Study by Biswal et al has shown that most of the cases who received multiple drugs outside before coming to emergency department had higher mortality and complications in comparison to those who did not receive any drug.[7] They have also stated that children admitted within 4 hours of the sting had much less complications than those who came later. Also it was mentioned that most of the cases with acute pulmonary oedema, encephalopathy and myocarditis were admitted 4 hours after the sting and had higher mortality and morbidity. In our study, $81.1 \%$ got admitted within 2 hours of sting and $90.6 \%$ had received prazosin within 4 hours of sting. Our study showed nil mortality. This may be due to early admission within 6 hours, early administration of prazosin and strict monitoring. Prazosin is a competitive post synaptic, alpha-1 adrenoceptor antagonist. Alpha receptor stimulation plays a major role in the evolution of clinical spectrum and prazosin suppresses the sympathetic outflow and decreases preload, afterload and blood pressure without increasing heart rate. The recommended dose is 30 micrograms per $\mathrm{kg}$ per dose. This was given to patients with evidence of autonomic storm. Dose was repeated at 3 hours and later every 6 hours till extremities are warm and pulses normal.

Study done by PK Devarbhavi et al has shown that hypertension is one of the commonest cardiovascular manifestations of scorpion sting envenomation; this is due to massive outpouring of catecholamines from adrenal medulla and also from postganglionic neurons. [8] In our study, systolic hypertension was observed in $28.9 \%$ and diastolic hypertension in $24.5 \%$ of the patients. Adult studies have shown higher incidence of hypertension ranging from 45 to $70 \%{ }^{[1]}$

Electrocardiographic changes frequently seen are peaked $\mathrm{T}$ waves in V2-6, ST segment elevation in leads $1, \mathrm{aVL}$, increased QR duration (Ventricular activation time) and $\mathrm{LVH}$ by voltage criteria. Low voltage complexes throughout the record and left anterior hemiblock indicate poor prognosis. In our study, tall $\mathrm{T}$ waves were seen in $4.3 \%$ and ST segment elevation in $1.87 \%$ children.

Prazosin was administered to $89.3 \%$ of the patients and majority $44 \%$ of them received 3 doses of prazosin. Study by Saminathan et al shows that early and effective prazosin therapy, good supportive care, close monitoring and management of complications can limit the resulting morbidity and mortality significantly.[9],[10]

Most of the patients in this study had class I symptoms and there was no death reported. These results are in accordance with those of Al Asmani et al in Saudi Arabia, where they had observed that majority of the patients showed local signs and symptoms and only $25 \%$ manifest systemic signs and symptoms.[11]

The time gap between the scorpion sting and presentation to the hospital is one of the significant risk factors, which determine better outcome and mortality. Studies by Ramesh Pol and Biswal $\mathrm{N}$ have showed that children who presented after 6 hours of the sting had a significantly higher mortality rate (7.5\%).[6],[7] In our study, no mortality or severe complications were encountered since all the children in the study group were admitted within 6 hours.

With nil mortality recorded in our study, the next important outcome of interest was duration of hospital stay. It was found that there was an association between severity of envenomation and duration of hospital stay as evidenced by uncomplicated cases getting discharged earlier. Among the individual parameters, cold extremities and ECG changes were associated significantly with prolonged hospital stay (More than 72 hours). There are no previous studies to determine the predictors of hospital stay.

The strength of our study is that it was done on a reasonable amount of data and was analysed using robust statistical methods. Limitations include presence of missing data, as it was a retrospective study done by analysis of case records. Further, sample size calculation was not done to determine risk factors for prolonged hospital stay.

\section{The following Preventive Measures may be Helpful}

1. Clearing the debris and trash in the dwelling areas.

2. Spraying pesticides.

3. Checking vigorously the clothing and bedding for scorpion before its use.

\section{CONCLUSION}

Clinical profile and demographic parameters of children with scorpion sting admitted in tertiary care centre are described. Cold extremities and ECG abnormalities are significantly associated with prolonged hospital stay.

\section{RECOMMENDATIONS}

Children with scorpion sting, presenting with cold extremities and ECG changes need close monitoring and management for a longer duration. Further, prospective studies with appropriate sample size calculations are required to determine poor prognostic features.

\section{REFERENCES}

1. Bawaskar HS, Bawaskar PH. Scorpion sting: update. JAPI 2012;60:46-55.

2. Abroug F, Nouira S, Saguiga H, et al. Envenomations scorpioniques: avancees chimiques, physio pathologiques et therapeutiques. Monograph 1994:1-68.

3. Mahadevan S. Scorpion sting. Indian Paediatrics 2000;37:504-14.

4. Das S, Nalini P, Ananthakrishnan S, et al. Scorpion envenomation in children in Southern India. J Trop Med Hyg 1995; 98(5):306-8.

5. Cesaretli Y, Ozkan O. Scorpion stings in Turkey: epidemiological and clinical aspects between the years 1995 and 2004. Rev Inst Med Trop Sao Paulo 2010;52(4):215-20. 
6. Pol R, Vanaki R, Pol M. The clinical profile and the efficacy of prazosin in scorpion sting envenomation in children of north Karnataka (India). Journal of Clinical and Diagnostic Research 2011;5(3):456-8.

7. Biswal N, Bashir RA, Murmu UC, et al. Outcome of scorpion sting envenomation after a protocol guided therapy. Indian J Paed 2006;73(7):577-82.

8. Devarbhavi PK, Murthy VCR. Scorpion sting envenomation-an overview. J Clin Biomed Sci 2013;3(4): 159-66.
9. Saminathan D, Thangavel A, Balaji K, et al. Clinical profile and outcome of scorpion sting in children between 1-12 years of age admitted in a tertiary care hospital. Journal of Evolution of Medical and Dental Sciences 2015;4(44):7597-603.

10. Bawaskar HS, Bawaskar PH. Prazosin in management of cardiovascular manifestations of scorpion sting. Lancet 1986;1(8479):510-1.

11. Al Asmari AK, Al Zahrani AG, Al Jowhary S, et al. Clinical aspects and frequency of scorpion stings in the Riyadh region of Saudi Arabia. Saudi Med J 2012;33(8):852-8. 